\title{
Increased Terpenoid Accumulation in Cotton (Gossypium hirsutum) Foliage is a General Wound Response
}

\author{
Stefan Opitz • Grit Kunert • Jonathan Gershenzon
}

Received: 4 December 2007 /Revised: 8 February 2008 / Accepted: 12 February 2008 /Published online: 2 April 2008

(C) The Author(s) 2008

\begin{abstract}
The subepidermal pigment glands of cotton accumulate a variety of terpenoid products, including monoterpenes, sesquiterpenes, and terpenoid aldehydes that can act as feeding deterrents against a number of insect herbivore species. We compared the effect of herbivory by Spodoptera littoralis caterpillars, mechanical damage by a fabric pattern wheel, and the application of jasmonic acid on levels of the major representatives of the three structural classes of terpenoids in the leaf foliage of 4-week-old Gossypium hirsutum plants. Terpenoid levels increased successively from control to mechanical damage, herbivory, and jasmonic acid treatments, with $E$ - $\beta$-ocimene and heliocide $\mathrm{H}_{1}$ and $\mathrm{H}_{4}$ showing the highest increases, up to 15 -fold. Herbivory or mechanical damage to older leaves led to terpenoid increases in younger leaves. Leaf-by-leaf analysis of terpenes and gland density revealed that higher levels of terpenoids were achieved by two mechanisms: (1) increased filling of existing glands with terpenoids and (2) the production of additional glands, which were found to be dependent on damage intensity. As the relative response of individual terpenoids did not differ substantially among herbivore, mechanical damage, and jasmonic acid treatments, the induction of terpenoids in cotton foliage appears to represent a non-specific wound response mediated by jasmonic acid.
\end{abstract}

Electronic supplementary material The online version of this article (doi:10.1007/s10886-008-9453-z) contains supplementary material, which is available to authorized users.

S. Opitz $(\bowtie) \cdot$ G. Kunert $\cdot$ J. Gershenzon

Department of Biochemistry,

Max Planck Institute for Chemical Ecology,

Hans-Knöll-Strasse 8,

07745 Jena, Germany

e-mail: opitz@ice.mpg.de
Keywords Gossypium hirsutum · Cotton · Spodoptera littoralis · Terpenoid aldehydes · Monoterpenes . Sesquiterpenes · Pigment glands · Constitutive plant defense · Jasmonic acid $\cdot$ Mechanical damage $\cdot$ Induction

\section{Introduction}

Plants produce a broad range of defense chemicals that act as deterrents or toxins against herbivores and pathogens. Several different strategies have evolved concerning the deployment of such compounds. When the synthesis of defense chemicals occurs solely after initial attack, this reduces metabolic costs (Gershenzon 1994), as defenses are produced only when needed. Such induced defenses have ecological advantages (Agrawal and Karban 1999) and might be a useful strategy for plants that are sporadically attacked. However, plants that risk frequent and heavy damage may be better protected by investing in constitutive defense compounds (Wittstock and Gershenzon 2002). The accumulation of constitutive defenses within plants usually conforms to expectations of the 'optimal defense theory' (ODT), which predicts that the highest protection level will be found in parts with the highest fitness value such as young tissues and reproductive organs (McKey 1979; Rhoades 1979). This has been shown for a variety of plant secondary metabolites from different classes such as alkaloids (Hartmann and Zimmer 1986; Baldwin 2001), glucosinolates (Porter et al. 1991. Brown et al. 2003), furanocoumarins (Berenbaum and Zangerl 1999), phenylpropanoids (Harborne 1991; Opitz and Schneider 2002), and terpenes (Gershenzon and Croteau 1991). Under abiotic or biotic stress, plants often exhibit induced responses by enhancing the accumulation of constitutive compounds in certain tissues that increases their deterrence or toxicity to 
enemies (Baldwin 1988; Wittstock and Gershenzon 2002; Vazquez-Flota et al. 2004). These changes also may be rationalized as a way for plants to reduce the costs of defense by producing high concentrations of constitutive defenses only when and where these are needed. However, more information is required to understand how the levels of constitutive defenses change under different stresses in plants on an organ-by-organ basis.

Among the vast number of defensive compounds in plants, terpenoids form the largest group with over 25,000 known structures (Buckingham 1994). Some of the beststudied examples for constitutive plant defenses are terpenoid volatiles such as monoterpenes $\left(\mathrm{C}_{10}\right)$, which are considered defensive against herbivores and pathogens (Gershenzon and Dudareva 2007). Monoterpenes are frequently constituents of oils and resins that are accumulated in complex secretory structures such as glandular trichomes, secretory cavities, or resin ducts (Fahn 1979). Among the most comprehensively studied systems are monoterpenes in the glandular trichomes of peppermint (Gershenzon et al. 2000; McConkey et al. 2000). However, less is known about the accumulation of other classes of terpenes.

Cotton (Gossypium hirsutum) is particularly suitable for the study of terpenoid accumulation because a large variety of terpenes are produced constitutively in all photosynthetically active parts of the plant and stored in subepidermal glands. Beside monoterpenes, G. hirsutum produces sesquiterpenes $\left(\mathrm{C}_{15}\right.$; Elzen et al. 1985) and terpenoid aldehydes, such as hemigossypolone $\left(\mathrm{C}_{15}\right)$ and the heliocides $\mathrm{H}_{1}$ to $\mathrm{H}_{4}$
$\left(\mathrm{C}_{25}\right.$; Fig. 1; Hedin et al. 1992). All three classes of terpenoids in cotton are biosynthetically related (Stipanovic et al. 1977, 1978a; Davis and Essenberg 1995). The precursor of sesquiterpenes, farnesyl diphosphate, is formed by addition of a $\mathrm{C}_{5}$ isopentenyl diphosphate unit to geranyl diphosphate, the precursor of all monoterpenes. The $\mathrm{C}_{25}$ heliocides are formed from Diels-Alder-type reactions of the $\mathrm{C}_{15}$ hemigossypolone (derived from $\delta$-cadinene) to the monoterpene myrcene for the formation of heliocides $\mathrm{H}_{2}$ and $\mathrm{H}_{3}$ or the monoterpene $E-\beta$-ocimene for the formation of heliocides $\mathrm{H}_{1}$ and $\mathrm{H}_{4}$ (Fig. 2).

The accumulation of terpenoid aldehydes in cotton leaves was shown to be increased after herbivory (Bezemer et al. 2004), and these compounds have been considered to function as feeding deterrents on generalist herbivores such as Spodoptera exigua (McAuslane et al. 1997). The heliocides specifically have been correlated with antifeedant effects and are locally and systematically induced in response to herbivore attack (Karban and Carey 1984; Croxford et al. 1989; Alborn et al. 1996). However, besides the terpenoid aldehydes, little information is available on the accumulation of other terpenes found in subepidermal glands. In studying the control of terpenoid accumulation in cotton, it is of interest to determine if higher concentrations arise from increases in gland number or from increases in the amount of terpenoids per gland (McAuslane et al. 1997). Increasing numbers of subepidermal glands in cotton leaves were observed after attacks of spider mites and caterpillars (McAuslane et al. 1997; Agrawal and Karban 2000).
Fig. 1 Terpenoid products of three structural classes, which are accumulated in glands of the foliage of Gossypium hirsutum. $1 \alpha$-pinene, 2 (E)- $\beta$-ocimene, 3 myrcene, 4 (E)- $\beta$-caryophyllene, $5 \gamma$ bisabolene, $6 \alpha$-humulene, 7 hemigossypolone, 8 heliocide $\mathrm{H}_{1}, 9$ heliocide $\mathrm{H}_{2}$

\section{Monoterpenes}<smiles>CC1=CC2CC1C2(C)C</smiles><smiles>C=C/C(C)=C/CC=C(C)C</smiles><smiles>C=CC(=C)CCC=C(C)C</smiles>

\section{Sesquiterpenes}<smiles>C=C1CC/C=C(/C)CCC2CC1CC2(C)C</smiles><smiles>CC(C)=CCCC(C)=C1CC=C(C)CC1</smiles><smiles>CC1=CCC(C)(C)CCCC(C)=CCC1</smiles>

Terpenoid aldehydes<smiles>[3H]C=C1C(=O)C=C(C)C(=O)c2c(O)c(O)c(C(C)C)c(C=O)c2C1=O</smiles><smiles>CC(C)=CCCC1=CCC2(C)C(=O)c3c(c(C=O)c(O)c(O)c3C(C)C)C(=O)C2C1</smiles> 
Fig. 2 Proposed scheme for the biosynthesis of heliocide $\mathrm{H}_{1}$ in cotton

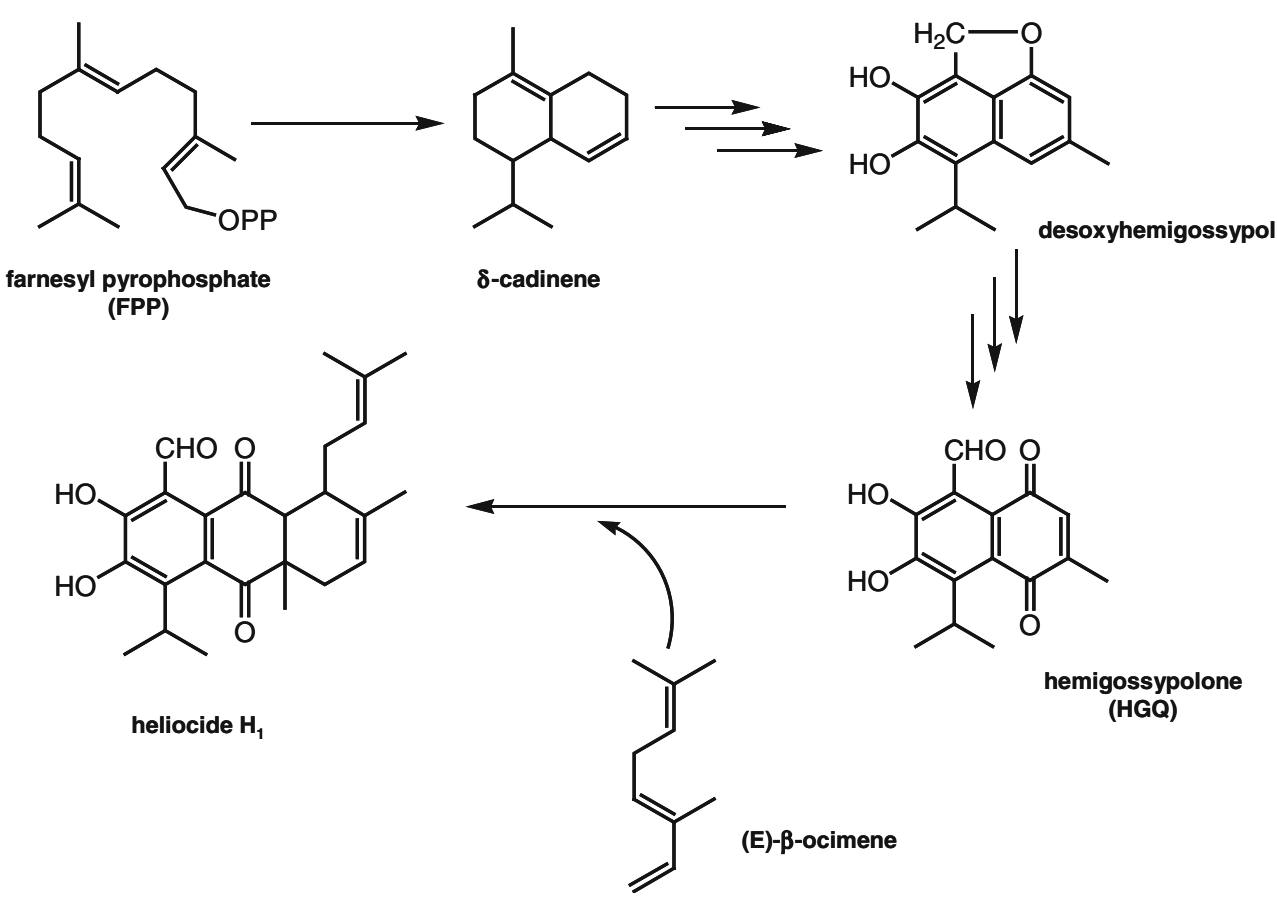

Herbivores Eggs of the generalist herbivore, Spodoptera littoralis (Boisd.; Lepidoptera, Noctuidae), Egyptian cotton worm, were obtained from Syngenta (Basel, Switzerland). After hatching, larvae were reared in 2-1 plastic boxes

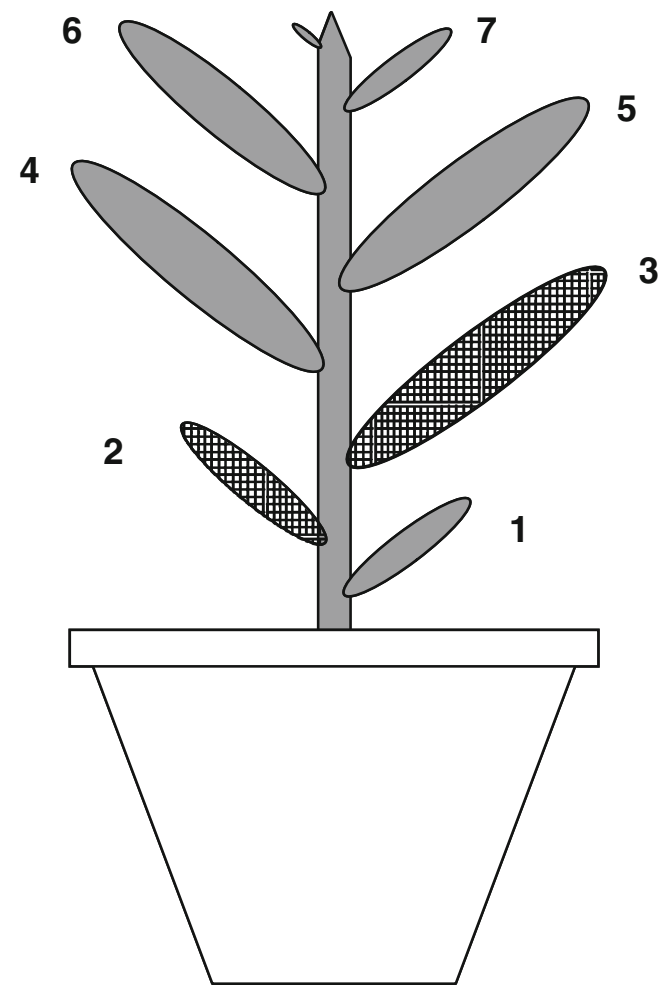

Fig. 3 Sketch of a Gossypium hirsutum plant at the end of experiment 1 , approximately 1 -month-old. Leaves are numbered according to the order of development. Grid pattern indicate leaves, which were damaged either mechanically or by caterpillars of Spodoptera littoralis 
containing artificial diet, which consisted of $500 \mathrm{~g}$ of bean flour, $500 \mathrm{ml}$ water, $9 \mathrm{~g}$ ascorbic acid, $5 \mathrm{~g}$ ethyl-4-benzoic acid, $0.6 \mathrm{ml} \alpha$-tocopherol, $9 \mathrm{ml}$ Mazola germ oil, $4 \mathrm{ml} \mathrm{3.7 \%}$

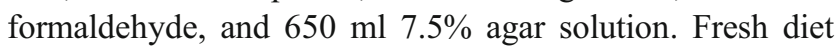
was applied every third day. Larvae were reared at constant $20^{\circ} \mathrm{C}, 50-60 \%$ relative humidity, and ambient light conditions. Two weeks after hatching, larvae reached the third instar and were used for the study.

\section{Experiment 1}

Treatment of Cotton Plants Three weeks after germination, when plants had developed four to five true leaves, the length of the midrib of leaf 4 was determined as a good measure for growth stage. Next, 24 plants at comparable growth stage were transferred into a second growth chamber (Vötsch, Germany) with abiotic conditions identical to the chamber where plants were reared. Here, plants were maintained separately in $250-\mathrm{ml}$ plastic pots and watered twice a day to ensure adequate water supply. After $24 \mathrm{~h}$, plants were divided into four treatment groups of six individuals each. Plants of one group were damaged mechanically three times on leaf 2 on the first day and three times on leaf 3 on the fourth day by using a fabric pattern wheel. In every case, leaves were scratched four times in parallel to the midrib (two times on each side). For a second group, three caterpillars of Spodoptera littoralis were caged on each plant on leaf 2 during the first day and on leaf 3 during the fourth day until larvae consumed at least one third of the available leaf material. Plants of the third group were watered with a $100-\mu \mathrm{M}$ JA solution in water (Sigma) during the first day. JA concentrations in this range are commonly used to induce the biosynthesis of secondary products in plants (Koch et al. 1999; van Poecke and Dicke 2002). Afterward, this solution was replaced by pure tap water. A control group of plants was not treated at all. One week after the start of treatments, all true leaves were harvested separately, frozen in liquid nitrogen, and stored at $-20^{\circ} \mathrm{C}$ until further analyses.

Foliar Glands Just after removal, all leaves were scanned to calculate leaf areas by using the program ImageJ (Wayne Rasband, National Institutes of Health, USA). In this procedure, herbivore-damaged leaves were used as templates to reconstruct the areas of undamaged leaves. In addition, surface view pictures were taken of two circular 24- $\mathrm{mm}^{2}$ sections from the center of each leaf half with a stereomicroscope connected to a digital camera. In doing so, leaves were illuminated from below with a lamp to visualize filled subepidermal glands as pigmented spots. After the number of filled glands was counted, gland densities for $24-\mathrm{mm}^{2}$ sections were calculated. Based on these sections, gland numbers and gland densities per leaf and per total foliage were extrapolated. These values were slightly underestimated because of higher gland densities at leaf edges (personal observations).

Analysis of Monoterpenes and Sesquiterpenes True leaves were separately analyzed for their content of constitutive terpenes. Depending on available material, $30-100 \mathrm{mg}$ of ground frozen leaf were extracted with $300-500 \mu$ l pentane/ $n$-hexane $1: 1$. Additionally, $2 \mu \mathrm{g}$ of nonylacetate were added as internal standard before extracts were shaken for $3 \mathrm{~h}$ at room temperature. After extracts were cooled to $4^{\circ} \mathrm{C}$, they were filtered through cotton and $\mathrm{Na}_{2} \mathrm{SO}_{4}$ to remove remaining water. A subset of extracts was analyzed qualitatively by gas chromatography-mass spectrometry (GC-MS) on a Hewlett-Packard 6890 gas chromatograph (injector temperature $220^{\circ} \mathrm{C} ; 1 \mu \mathrm{l}$ splitless injection) coupled to a Hewlett-Packard 5973 quadrupole mass selective detector. Separations were performed on a DB$5 \mathrm{MS}$ column $(30 \mathrm{~m} \times 0.25 \mathrm{~mm} \times 0.25 \mu \mathrm{m}$ film; Agilent Technology) with $2 \mathrm{ml} \mathrm{min}^{-1}$ helium as the carrier gas. The following temperature gradient was used: $40^{\circ} \mathrm{C}$ for $3 \mathrm{~min}$, increased to $90^{\circ} \mathrm{C}$ at $5^{\circ} \mathrm{C} / \mathrm{min}$, further increased to $140^{\circ} \mathrm{C}$ at $40^{\circ} \mathrm{C} / \mathrm{min}$, followed by an increase to $160^{\circ} \mathrm{C}$ at $4^{\circ} \mathrm{C} / \mathrm{min}$, maintained at $160^{\circ} \mathrm{C}$ for $3 \mathrm{~min}$, and a final heating to $300^{\circ} \mathrm{C}$ for $3 \mathrm{~min}$. Mass spectrometry was performed with an ionization potential of 70 electron volts and a scan range of $\mathrm{m} / \mathrm{z}$ from 50 to 300 . Compound identification was based on comparisons with mass spectra in the Wiley and National Institute of Standards and Technology (NIST) libraries or on direct comparison of mass spectra and retention times with available standards. For quantification, all samples were analyzed on a Hewlet-Packard 6890 gas chromatograph and a flame ionization detector (temperature $250^{\circ} \mathrm{C}$ ). The separation procedure was identical to the method for GC-MS analysis. Terpenes were quantified by using nonylacetate and corrected with response factors according to Scanlon and Willis (1985). Concentrations and levels of terpenes per subepidermal gland were calculated for single leaves and for total foliage. Eight individual monoterpenes and sesquiterpenes were analyzed, which represent more than $90 \%$ of the total terpenes in G. hirsutum.

Analysis of Terpenoid Aldehydes True leaves were separately analyzed for their content of terpenoid aldehydes according to Stipanovic et al. (1988). Depending on available material, $30-100 \mathrm{mg}$ of ground frozen material were extracted $\times 3$ with $3 \mathrm{ml}$ of ethyl acetate $/ n$-hexane (1:3) and $50 \mu \mathrm{l}$ of $10 \% \mathrm{HCL}$. Extracts were shaken at $5^{\circ} \mathrm{C}$ for $3 \mathrm{~h}$. Afterwards, extracts were removed from the leaf material, evaporated with nitrogen, and redissolved in $40 \%$ $\mathrm{H}_{2} \mathrm{O}$ and $60 \%$ solvent $\mathrm{B}$ (see below) from the following high-performance liquid chromatography (HPLC) proce- 
dure. Reversed phase HPLC analysis was performed on a Chromolith LC-18 column (Merck; $5 \mu \mathrm{m} ; 100 \times 4 \mathrm{~mm}$ ) with single wavelength detection at $272 \mathrm{~nm}$. The column was eluted with $\mathrm{H}_{2} \mathrm{O}+0.05 \%$ trifluoracetic acid (solvent $\mathrm{A}$ ) and EtOH/MeOH/MeCN/EtOAc/iPrOH, 26.6:7.4:40.5:6.1:19.4 (solvent B), with the following gradient: 50\% B (0 min)$50 \%$ B (5 min)-61\% B (5.1 min)-61\% B (20 min). Flow rate was held constant at $2 \mathrm{ml} \mathrm{min}^{-1}$, and temperature was kept at $25^{\circ} \mathrm{C}$. Five compounds, the hemigossypolone $\left(\mathrm{C}_{15}\right)$ and the heliocides 1-4 $\left(\mathrm{C}_{25}\right)$, were identified by their retention times according to the literature (Stipanovic et al. 1988) and additionally by liquid chromatography-mass spectrometry (LC-MS) measurements. Quantification was done by using standard curves of purified compounds. Concentrations and levels per subepidermal gland were calculated for single leaves and for the total foliage. Hemigossypolone and the four heliocides represent approximately $90 \%$ of the total terpenoid aldehyde content. As a sesquiterpene aldehyde, hemigossypolone was included in our analysis with other terpenoid aldehydes rather than with the sesquiterpenes. In comparison to other cotton varieties (Bezemer et al. 2004), the terpenoid aldehyde gossypol $\left(\mathrm{C}_{30}\right)$ was found only in traces by LC-MS and was not quantified.

\section{Experiment 2}

Eighteen 2-wk-old plants at the growth stage of two true leaves were chosen and prepared for treatments in a way comparable to the first experiment. Plants were divided into three groups. Plants of one group were damaged mechanically nine times on leaves 1 and 2 during six consecutive days by using a mechanical fabric pattern wheel (procedure see experiment 1). For a second group, two caterpillars of Spodoptera littoralis were caged on each plant on one cotyledon during day 1 , on leaf 1 during day 3 , and on leaf 2 during day 5 until larvae consumed at least one third of the available leaf material. A control group was not treated at all. One week after the start of treatments, leaf 4 from each plant was harvested. Leaf areas and gland number per leaf were determined according to experiment 1. Afterwards, leaves were frozen in liquid nitrogen and stored at $-20^{\circ} \mathrm{C}$ until further analyses of mono- and sesquiterpenes. Levels of terpene classes were calculated based on the levels of eight individual compounds that represent more than $90 \%$ of the accumulated monoterpenes and sesquiterpenes in G. hirsutum.

\section{Statistics-Experiment 1}

Total Foliage The effects of mechanical damage, herbivory, and JA application on foliage area, levels of total mono- terpenes, sesquiterpenes, and terpenoid aldehydes, as well as on levels of individual major terpenoids, were analyzed with analyses of variance. Data were tested for normality and equal variances. For normally distributed data, one-way analyses of variance (ANOVAs) were used. Differences between treatments and controls were tested for significance by using Dunn's post hoc tests. Data not normally distributed were analyzed by using Kruskall-Wallis oneway ANOVAs on ranks and Dunn's post hoc tests. Analyses were performed with Sigma Stat 2.03. The effect of foliage area and treatment on the total number of glands was tested by analysis of codeviance. Generalized linear models (GLM) with the log link as link function were performed. To deal with overdispersion, a quasi-Poisson distribution was used in the models instead of Poisson distribution. The models were simplified by removing nonsignificant terms and by factor-level reduction (Crawley 2002). These analyses were performed in $R$, version 2.4.1. All data are presented as mean $\pm \mathrm{SE}$ except when it is mentioned otherwise.

Single Leaves The effects of leaf position, treatment, and their interactions on levels of terpenoids per gland were tested by using nested two-way ANOVA. For this purpose, terpenoid data were root- or log-transformed to normalize them. For single leaf positions, the effects of the treatments on the leaf area were tested with one-way ANOVAs. The effect of leaf area and treatment on the total number of glands was tested by analysis of codeviance (GLM see above). To analyze the effect of leaf area and treatment on gland density, levels of terpenoids per gland and terpenoid concentrations per milligram fresh leaf material ANCOVAs were used. These analyses were performed in $R$, version 2.4.1. Changes in per gland concentrations of individual terpenoids at specific leaf positions after treatments were tested with Sigma Stat 2.03. For normally distributed data, one-way ANOVAs were used. Differences between treatments and controls were tested for significance by using Dunn's post hoc tests. Data not normally distributed were analyzed using Kruskall-Wallis one-way ANOVAs on ranks and Dunn's post hoc tests.

\section{Statistics-Experiment 2}

Single Leaves The effect of the treatments on the areas of leaf 4 was tested with one-way ANOVA. The effect of leaf area and treatment on the total number of glands was tested by analysis of codeviance (GLM see above). To analyze the influence of leaf area and treatments on the accumulation of mono- and sesquiterpenes an ANCOVA was achieved. All analyses were performed in $R$, version 2.4.1. 


\section{Results}

\section{Experiment 1}

Terpenoid Accumulation in Total Cotton Foliage after Induction The accumulation of terpenoid classes among the four different treatments was first compared on the basis of total foliage (Fig. 4). For monoterpenes, sesquiterpenes, and terpenoid aldehydes, there was a gradual increase in the following order: control, mechanical damage, herbivory, and JA treatment (ANOVA on ranks: monoterpenes, $H=$ 9.420, $P=0.024$; sesquiterpenes, $H=14.140, P=0.003$; terpenoid aldehydes, $H=19.760, P<0.001)$. Levels of all three classes were elevated in herbivore-damaged (Dunn's tests: monoterpenes, $Q=2.572$; sesquiterpenes, $Q=2.490$; aldehydes, $Q=2.939$; all $P<0.05$ ) and JA-treated plants (Dunn's tests: monoterpenes, $Q=2.735$; sesquiterpenes, $Q=3.674$; aldehydes, $Q=4.164$; all $P<0.05$ ) in comparison to the controls.

All individual compounds showed the same pattern that was seen for total terpenoid accumulation: a gradual increase from control to mechanical damage, herbivory, and JA treatment. In 11 out of 13 compounds, this increase was significant (Table 1) for herbivore and JA-treated plants compared to the control plants, while mechanically damaged plants showed tendencies for increased accumulation. Among monoterpenes, considerable differences in accumulation after treatment were shown. (E)- $\beta$-ocimene increased up to eightfold after both herbivory and JA treatment in comparison to controls, whereas myrcene levels slightly but significantly increased after herbivory and JA treatment, and the amounts of $\alpha$ - and $\beta$-pinene did not show significant differences between treatments and control. Little variation in the induction pattern occurred when comparing individual sesquiterpenes. Levels of all major sesquiterpenes, including $\beta$-caryophyllene, $\alpha$ humulene, $\gamma$-bisabolene, and $\beta$-bisabolol doubled after herbivory and were 2.0-2.6-fold higher after JA treatment in comparison to control plants. Among terpenoid alde- hydes, considerable differences appeared. Whereas the amounts of hemigossypolone were doubled, levels of heliocides, especially $\mathrm{H}_{1}$ and $\mathrm{H}_{4}$, increased much more after herbivory and JA treatment compared to the controls. Heliocide $\mathrm{H}_{4}$, for example, showed up to a ninefold increase after herbivory and up to a 15-fold increase after JA treatment in comparison to control plants. For $\mathrm{H}_{1}$, these increases were approximately five- and tenfold, respectively. Meanwhile, the highest levels of $\mathrm{H}_{2}$ and $\mathrm{H}_{3}$ were found in the JA-treated plants, reaching up to 3.3-fold that of control levels.

Growth and Subepidermal Gland Production of Cotton Foliage ANOVA showed an effect of the treatments on the total leaf area $(F=10.44, P<0.001)$. Whereas controls, mechanically and herbivore-damaged plants were highly comparable in size (mean, $496-513 \mathrm{~cm}^{2}$ ), JA-treated plants (mean $=306 \mathrm{~cm}^{2}$ ) showed a reduction in the total area of foliage down to $60 \%$ that of the controls (Bonferoni post hoc test. $P<0.05$ ).

Because of significantly smaller leaves in the JA-treated plants, the effect of treatment on the production of subepidermal glands was tested by using a GLM with leaf area as a covariable. For all treatments, this covariable showed an impact on the number of glands $(t=8.113, P<$ 0.001; Fig. 5). In comparison to the controls, an increase in the number of glands was found for herbivore-damaged plants $(t=4.147, P<0.001)$ and for plants that were treated with JA $(t=5.585, P<0.001)$. Because there were no differences between mechanically damaged and non-treated plants, the data of both groups were combined in this analysis.

Single Leaf Analysis To assess more precisely plant response to the treatments, analyses were carried out at the level of individual leaves. For all treatments, the distribution of leaf areas followed a consistent pattern within plants with the biggest leaves at intermediate positions (Fig. 6a). Whereas no differences in leaf area

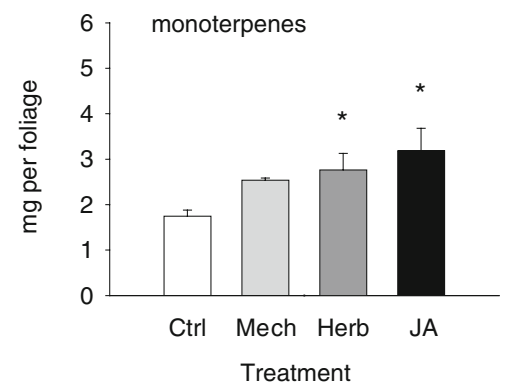

Fig. 4 Mean $( \pm$ SE, $N=6)$ levels of terpenoids in the total foliage of 4week-old cotton plants, which were either damaged at leaves 2 and 3 mechanically (Mech), fed upon by larvae of Spodoptera littoralis (Herb), treated with jasmonic acid $(J A)$, or left as untreated controls
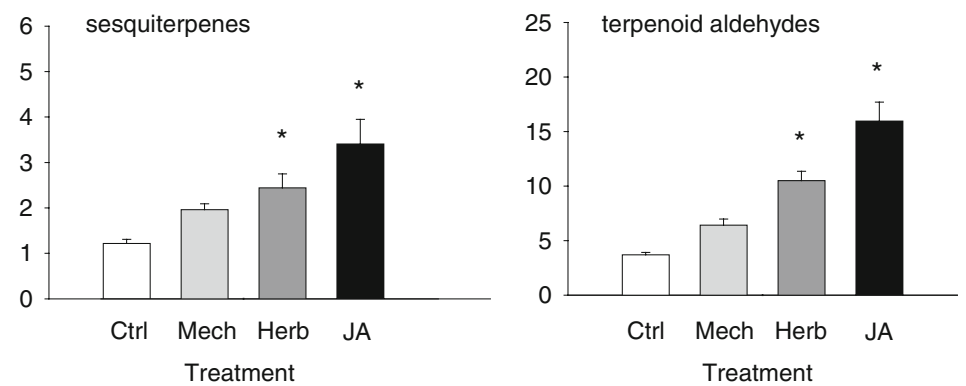

(Ctrl) 7 days previously. Asterisks indicate significant differences between treatment and control plants based on Kruskall-Wallis oneway ANOVAs on ranks and Dunn's post hoc tests. ${ }^{*} P<0.05$ 
Table 1 Mean levels ( $\pm \mathrm{SD}, N=6$ ) of terpenoid products in total foliage of 1-month-old G. hirsutum plants that were either mechanically damaged with a fabric pattern wheel, damaged by larvae of Spodoptera littoralis (herbivory), treated with jasmonic acid (JA), or left as untreated controls

\begin{tabular}{|c|c|c|c|c|c|c|}
\hline \multirow[t]{2}{*}{ Compound } & \multicolumn{2}{|c|}{$\operatorname{ANOVA}(d f=3)$} & \multicolumn{4}{|c|}{ Levels of terpenoids (mg) } \\
\hline & $F / H$ & $P$ Value & Control & Mechanical damage & Herbivory & $\mathrm{JA}$ \\
\hline \multicolumn{7}{|l|}{ Monoterpenes } \\
\hline$\alpha$-Pinene & 7.213 & 0.065 & $1.11 \pm 0.08$ & $1.26 \pm 0.11$ & $1.31 \pm 0.25$ & $1.45 \pm 0.44$ \\
\hline$\beta$-Pinene & 7.647 & 0.054 & $0.20 \pm 0.02$ & $0.23 \pm 0.02$ & $0.25 \pm 0.05$ & $0.26 \pm 0.08$ \\
\hline Myrcene & 10.167 & 0.017 & $0.49 \pm 0.06$ & $0.68 \pm 0.04$ & $0.78 * * \pm 0.15$ & $0.80 * * \pm 0.33$ \\
\hline (E)- $\beta$-Ocimene & 17.487 & $<0.001$ & $0.06 \pm 0.02$ & $0.25 \pm 0.06$ & $0.47 * * \pm 0.11$ & $0.49 * * \pm 0.26$ \\
\hline \multicolumn{7}{|l|}{ Sesquiterpenes } \\
\hline (E)- $\beta$-Caryophyllene & 16.340 & $<0.001$ & $0.50 \pm 0.07$ & $0.76 \pm 0.12$ & $0.95 * * \pm 0.21$ & $1.32 * * \pm 0.50$ \\
\hline$\alpha$-Humulene & 9.509 & $<0.001$ & $0.14 \pm 0.02$ & $0.22 \pm 0.03$ & $0.27 * \pm 0.06$ & $0.36 * \pm 0.13$ \\
\hline$\gamma$-Bisabolene & 18.007 & $<0.001$ & $0.23 \pm 0.04$ & $0.34 \pm 0.06$ & $0.45 * * \pm 0.10$ & $0.60 * * \pm 0.19$ \\
\hline$\beta$-Bisabolol & 14.340 & 0.002 & $0.46 \pm 0.05$ & $0.59 \pm 0.09$ & $0.82 * * \pm 0.18$ & $0.91 * * \pm 0.26$ \\
\hline \multicolumn{7}{|l|}{ Terpenoid aldehydes } \\
\hline Hemigossypolone & 15.287 & 0.002 & $1.59 \pm 0.30$ & $2.16 \pm 0.44$ & $3.14 * * \pm 0.40$ & $3.10 * * \pm 0.83$ \\
\hline Heliocide 1 & 20.487 & $<0.001$ & $0.59 \pm 0.14$ & $1.65 \pm 0.37$ & $3.35 * * \pm 1.11$ & $5.95 * * \pm 1.93$ \\
\hline Heliocide 2 & 21.031 & $<0.001$ & $0.97 \pm 0.21$ & $1.45 \pm 0.42$ & $1.83 * \pm 0.37$ & $3.06 * \pm 0.74$ \\
\hline Heliocide 3 & 23.938 & $<0.001$ & $0.37 \pm 0.07$ & $0.56 \pm 0.15$ & $0.70 * \pm 0.15$ & $1.23 * \pm 0.30$ \\
\hline Heliocide 4 & 20.247 & $<0.001$ & $0.17 \pm 0.08$ & $0.59 \pm 0.25$ & $1.47 * * \pm 0.39$ & $2.60 * * \pm 0.78$ \\
\hline
\end{tabular}

The effect of treatment on terpenoid levels were tested using one-way ANOVAs. For normally distributed data, one-way ANOVAs were performed ( $F$ values). For not normally distributed data, Kruskall-Wallis one-way ANOVAs on ranks were performed $(H$ values).

$* P<0.05$, significant differences from the control according to Bonferoni post hoc tests

**P $P<0.05$, significant differences from the control according to Dunn's post hoc tests

were evident among mechanically damaged, herbivoredamaged, and control plants, plants treated with JA exhibited significant smaller areas for leaves 3-6 in comparison to corresponding control leaves (ESM Tables 3 and 4). Because of the negative impact of JA treatment on the leaf area, the following analyses of the effect of treatments on gland and terpenoid production were

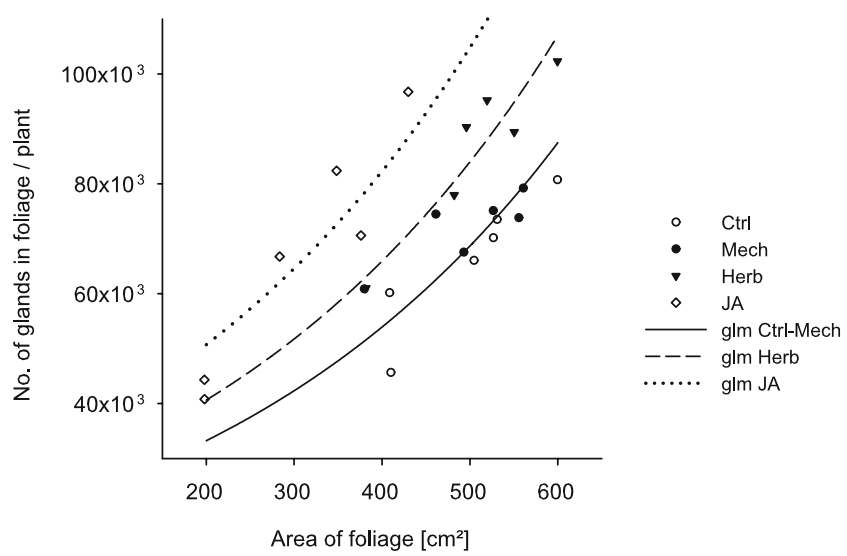

Fig. 5 Effect of leaf area and treatment on the number of glands in the total foliage of 4-week-old cotton plants, which were either damaged at leaves 2 and 3 mechanically (Mech), fed upon by larvae of Spodoptera littoralis (Herb), treated with jasmonic acid (JA), or left as untreated controls $(\mathrm{Ctrl}) 7$ days previously. Regressions were drawn based on transformed data from a generalized linear model $(G L M)$ with a quasi-Poisson error distribution. Data for control and mechanically damaged plants were combined due to factor level reduction performed by using leaf area as covariable (statistical results see ESM Tables 3 and 4).

Gland number per leaf revealed a similar distribution pattern among leaves for all treatments: The oldest leaf 1 contained the lowest gland number, which increased gradually toward leaf 5 and again decreased in the expanding leaves 6 and 7 (Fig. 6b). Young leaves (5-7) of herbivore-treated plants showed significantly elevated numbers of glands in comparison to corresponding leaves of control plants. Lower but still significant increases in gland numbers were found for leaves 2, 3, and 7 (youngest leaf) of plants that were treated with JA compared to control leaves. Mechanical damage showed nearly no effect on gland number.

Changes in leaf area and gland numbers after treatment should have an impact on gland densities. Independent of treatment, gland densities increased gradually from the oldest leaf 1 toward the youngest leaf 7 (Fig. 6c). This pattern was enhanced in herbivore-damaged and JA-treated plants because of significantly higher gland densities in young leaves $(5,6,7)$ compared to those leaves from the control plants. Mechanical damage did not cause an increased gland density in any leaf.

To analyze how terpenoid production was altered by treatment, total terpenoid levels per gland were calculated. Treatments had a considerable effect on the pattern of terpenoids per gland among leaves (Fig. 6d). Control plants showed highest levels in the oldest leaf and lowest levels in the youngest one. In contrast, mechanically and herbivore- 
Fig. 6 Mean $( \pm \mathrm{SE}, N=3-6)$ leaf area, number of glands, gland density, terpenoid level per gland, and terpenoid concentration of 4-week-old cotton plants, which were either damaged at leaves 2 and 3 mechanically (Mech), fed upon by larvae of Spodoptera littoralis (Herb), or treated with jasmonic acid (JA) 7 days previously. Areas of herbivore-damaged leaves 2 and 3 were extrapolated from remaining leaf material. For each leaf position, asterisks indicate significant differences from corresponding control leaves based on one-way ANOVAs (a), on analyses of codeviance with leaf area as covariable (b), and ANCOVAs with leaf area as covariable (c-e). ${ }^{*} P<0.05$

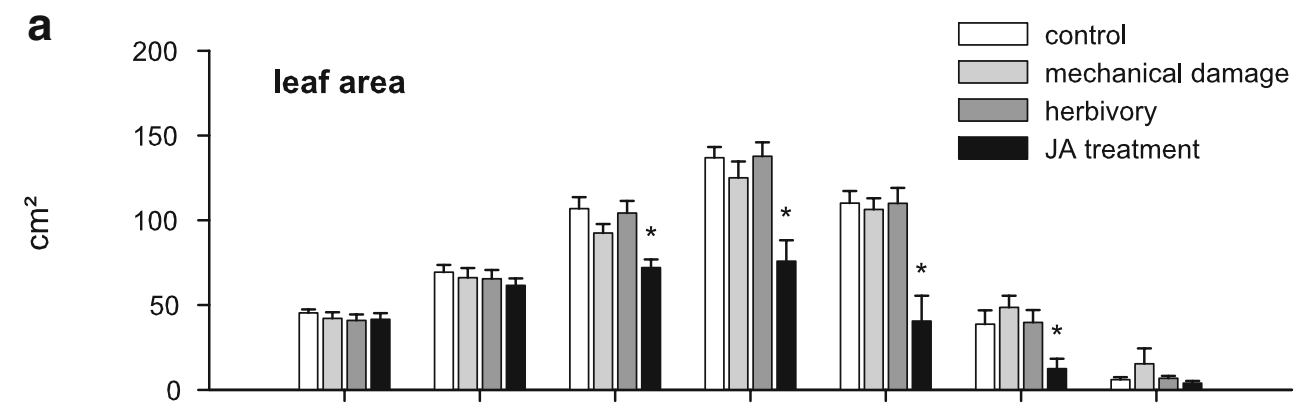

b

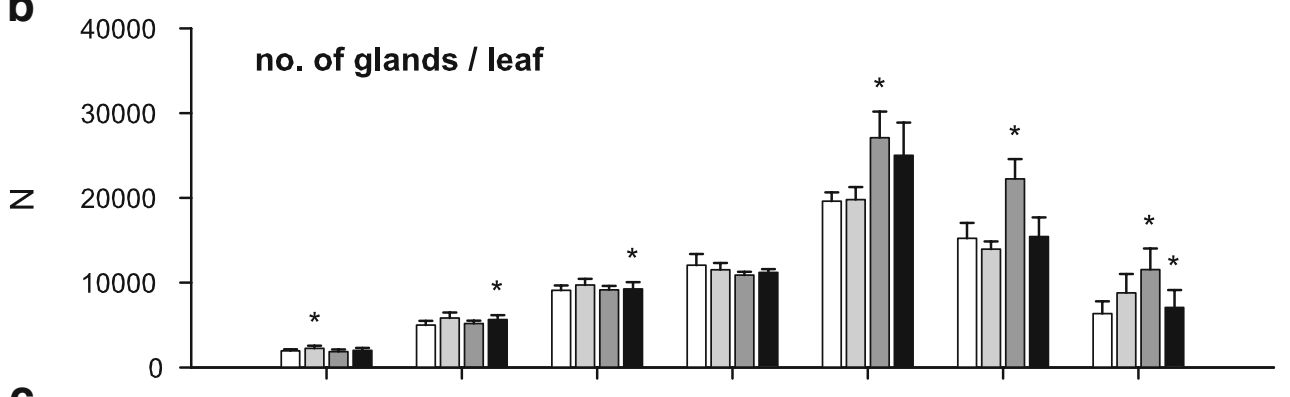

C
$\frac{\sigma}{d}$
$\frac{0}{\sigma}$
$\frac{0}{\Phi}$
$\frac{\Phi}{N}$
$\frac{0}{0}$
$\frac{c}{0}$
$\frac{0}{0}$
$\frac{0}{\sigma}$
$\frac{\pi}{0}$

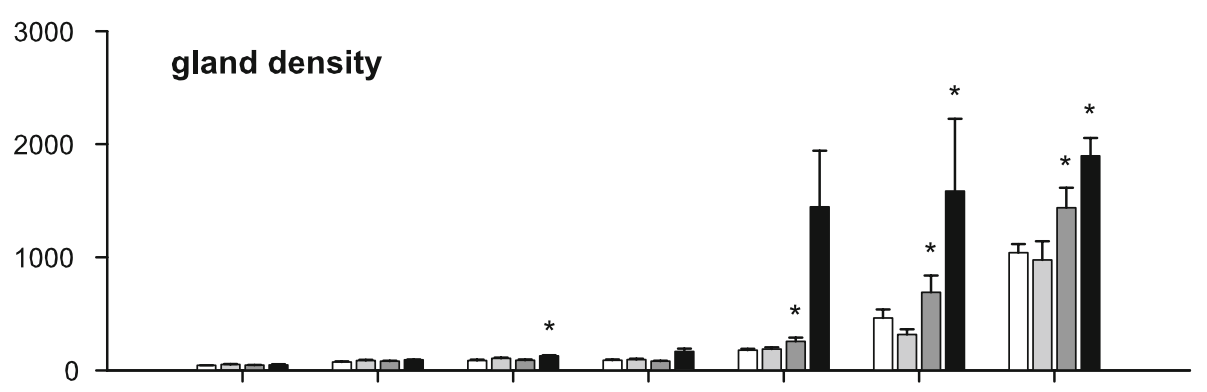

d

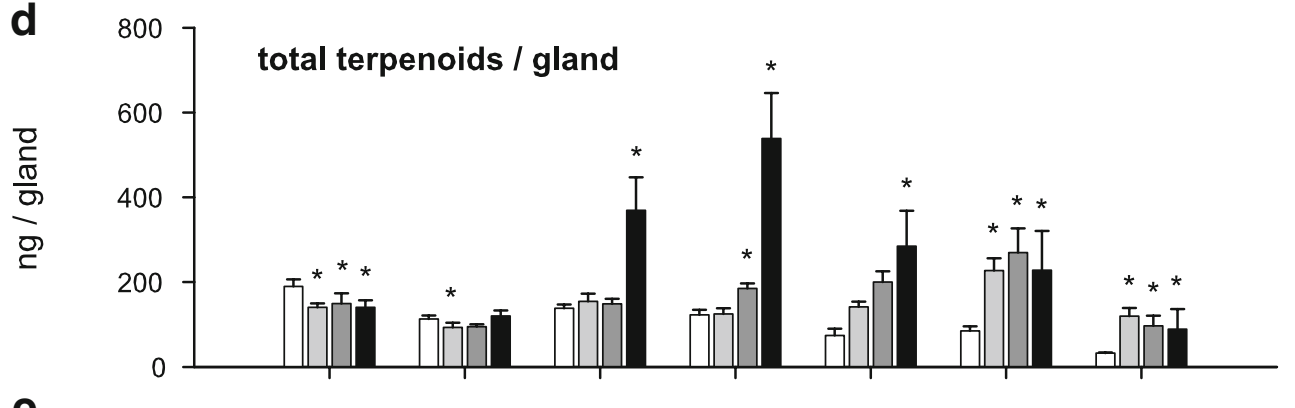

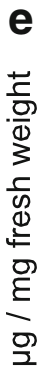

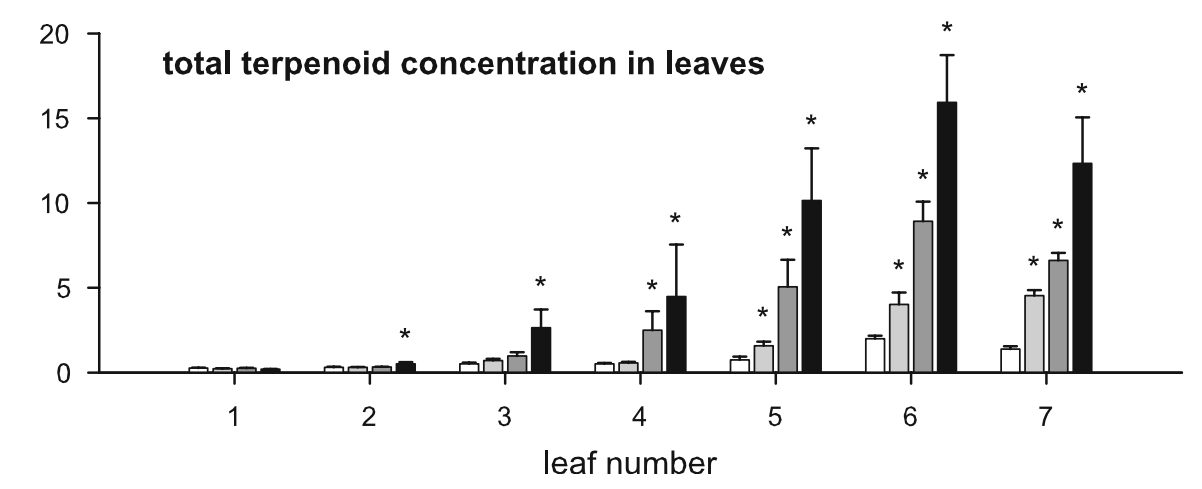


damaged plants exhibited highest values in younger leaves, having significantly elevated total terpenoid levels in comparison to those of control leaves. Plants that were treated with JA showed significantly elevated levels of total terpenoids per gland in young and intermediate leaves in comparison to the controls.

The increase in total terpenoid and gland production caused by the treatments as well as altered leaf areas had a considerable impact on the pattern of the total terpenoid concentrations in leaves. Total terpenoid concentrations showed a consistent distribution pattern among leaves for all treatments (Fig. 6e). There was a gradual increase starting from the oldest leaf 1 toward the youngest leaves 6 and 7. All treatments enhanced this pattern by causing significantly higher concentrations in intermediate and young leaves in comparison to the leaves of corresponding control plants. The lowest effect was found for mechanically damaged plants, whereas plants treated with JA reached the highest concentration with mean levels of approximately $16 \mu \mathrm{g}$ terpenoids per milligram fresh weight.

The analyses of individual terpenoids revealed a significant impact of treatment, leaf position, and interactions between these two factors on levels of all compounds per gland (Table 2). The lowest effects of treatment were found for the monoterpenes $\alpha$ - and $\beta$-pinene, whereas the biggest changes appeared for $(E)$ - $\beta$-ocimene and heliocides 1 and 4. Differences of single terpenoid levels per gland among leaves appeared to be biggest for $(E)$ - $\beta$-ocimene and heliocides 4 , but in case of the latter, this was due to its unusual absence in leaves 2 and 3 (Fig. 7). Significant interactions between treatment and leaf position revealed that changes in levels of total and single terpenoids of induced plants were not consistent in all leaves, which is illustrated in Fig. 7. As with total terpenoid levels per gland (Fig. 6d), mechanical damage and herbivory caused significantly elevated accumulation of individual compounds per gland in the youngest leaves in comparison to control plants. In contrast, JA treatment induced elevated levels in young but also in intermediate leaves compared to control leaves. JA treatment led to the highest increases of most compounds, especially for heliocides, in comparison to those in the corresponding leaves of control plants.

\section{Experiment 2}

Morphological and Chemical Changes in Young Leaves after Induction In addition to herbivore-treated plants and untreated controls, this supplementary experiment also included mechanically damaged plants that were injured more frequently and over a longer period than in experiment 1. ANOVA showed an effect of the treatments on areas of young leaves (leaf $4 ; F=5.97, P=0.012$; Fig. 8a, ESM Table 5). Herbivory reduced the areas of these leaves in comparison to those of the corresponding leaves of the control plants $(t=-3.445, P=0.004)$. Therefore, the effect of mechanical damage and herbivory on the production of glands were tested by using a GLM with leaf area as a covariable. For both treatments, leaf area showed an impact on the number of glands $(t=2.256, P=0.041)$. In comparison to the control plants, a significant increase in the number of glands was found for mechanically damaged plants $(t=2.599, P<0.021)$ and an even more pronounced

Table 2 Results of nested two-way ANOVA for the effects of treatment (mechanical damage, herbivory, jasmonic acid application), leaf position, and interactions on levels of accumulated terpenoids per gland in plants of G. hirsutum

\begin{tabular}{|c|c|c|c|c|c|c|}
\hline \multirow[t]{2}{*}{ Compound } & \multicolumn{2}{|c|}{ Treatment $(d f=3)$} & \multicolumn{2}{|c|}{ Leaf Number $(d f=6)$} & \multicolumn{2}{|c|}{ Treatment $\times$ Leaf Number $(d f=18)$} \\
\hline & $F$ & $P$ & $F$ & $P$ & $F$ & $P$ \\
\hline Total terpenoids & 37.81 & $<0.001$ & 17.45 & $<0.001$ & 6.78 & $<0.001$ \\
\hline \multicolumn{7}{|l|}{ Monoterpenes } \\
\hline$\alpha$-Pinene & 6.70 & $<0.001$ & 39.98 & $<0.001$ & 4.02 & $<0.001$ \\
\hline$\beta$-Pinene & 4.34 & 0.006 & 42.48 & $<0.001$ & 3.67 & $<0.001$ \\
\hline Myrcene & 10.25 & $<0.001$ & 51.60 & $<0.001$ & 4.06 & $<0.001$ \\
\hline (E)- $\beta$-Ocimene & 106.72 & $<0.001$ & 79.24 & $<0.001$ & 6.50 & $<0.001$ \\
\hline \multicolumn{7}{|l|}{ Sesquiterpenes } \\
\hline (E)- $\beta$-Caryophyllene & 24.13 & $<0.001$ & 13.30 & $<0.001$ & 6.59 & $<0.001$ \\
\hline$\alpha$-Humulene & 20.56 & $<0.001$ & 9.66 & $<0.001$ & 3.21 & $<0.001$ \\
\hline$\gamma$-Bisabolene & 37.08 & $<0.001$ & 11.33 & $<0.001$ & 5.74 & $<0.001$ \\
\hline$\beta$-Bisabolol & 23.15 & $<0.001$ & 12.48 & $<0.001$ & 4.99 & $<0.001$ \\
\hline \multicolumn{7}{|l|}{ Terpenoid aldehydes } \\
\hline Hemigossypolone & 10.16 & $<0.001$ & 15.48 & $<0.001$ & 6.47 & $<0.001$ \\
\hline Heliocide 1 & 64.63 & $<0.001$ & 13.78 & $<0.001$ & 8.88 & $<0.001$ \\
\hline Heliocide 2 & 27.13 & $<0.001$ & 17.65 & $<0.001$ & 4.94 & $<0.001$ \\
\hline Heliocide 3 & 30.60 & $<0.001$ & 17.66 & $<0.001$ & 4.83 & $<0.001$ \\
\hline Heliocide 4 & 55.70 & $<0.001$ & 104.05 & $<0.001$ & 8.59 & $<0.001$ \\
\hline
\end{tabular}



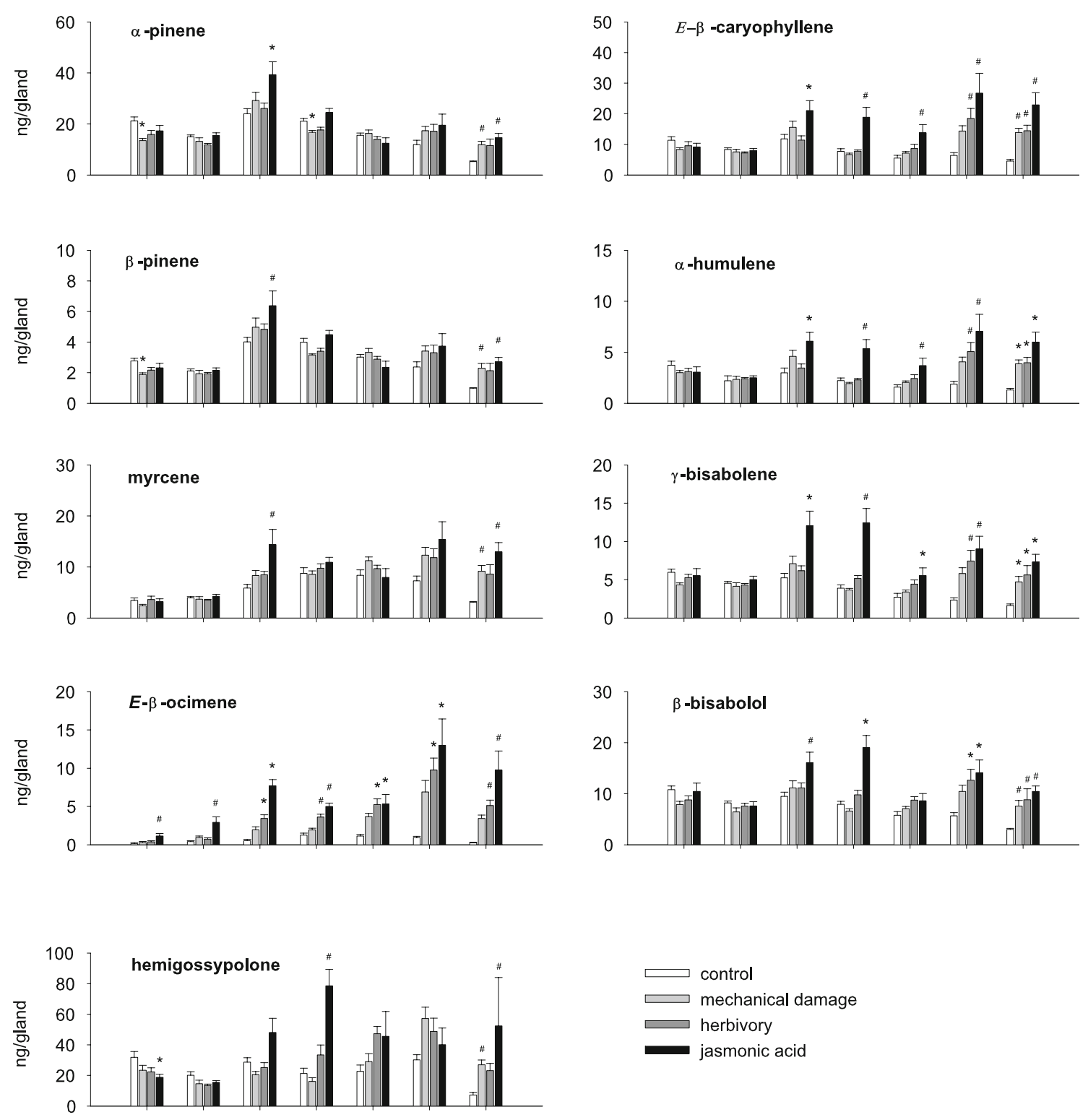

$$
\begin{aligned}
& \square \text { control } \\
& \text { mechanical damage } \\
& \text { herbivory } \\
& \text { jasmonic acid }
\end{aligned}
$$
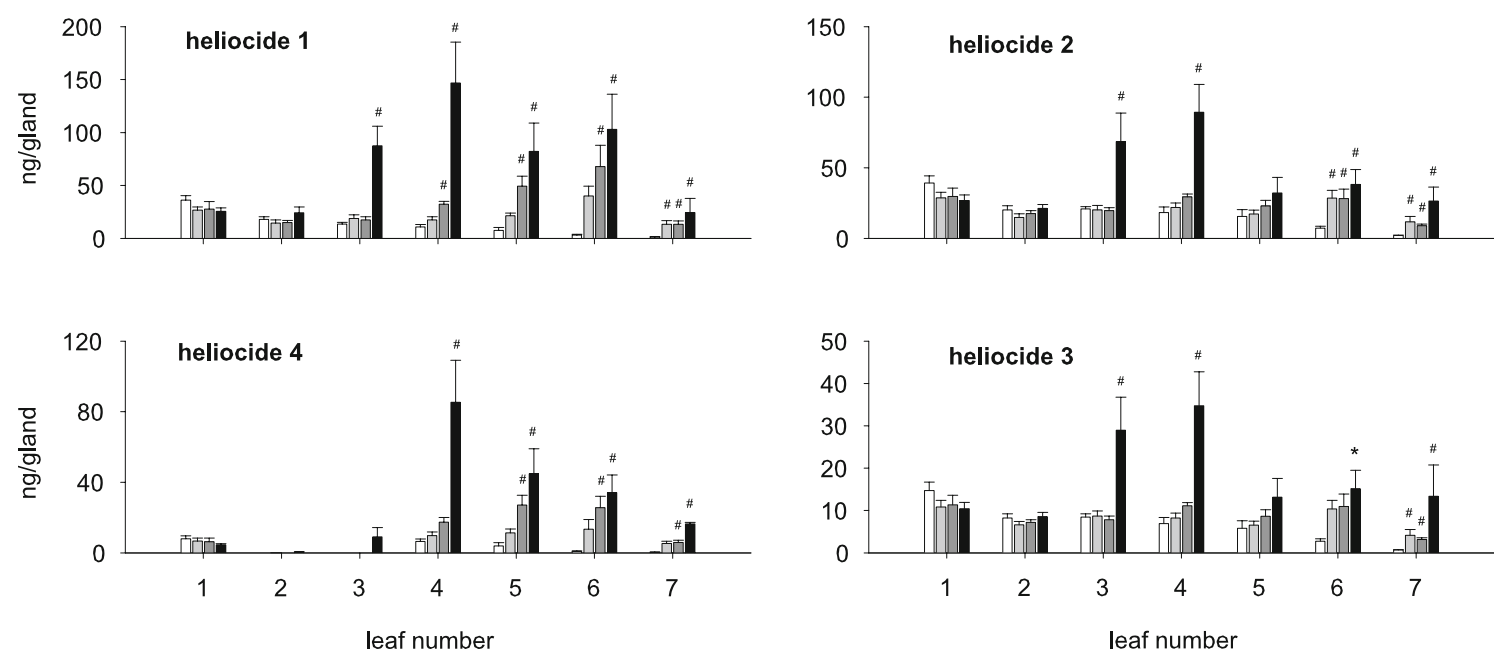
4Fig. 7 Mean $( \pm \mathrm{SE}, N=3-6)$ concentrations of terpenoids per gland among true leaves of 4-week-old Gossypium hirsutum plants, which were either damaged at leaves 2 and 3 mechanically (Mech), fed upon by larvae of Spodoptera littoralis (Herb), treated with jasmonic acid $(\mathrm{JA})$, or left as untreated controls $(\mathrm{Ctrl}) 7$ days previously. Asterisks indicate significant differences $(P<0.05)$ from corresponding control leaves based on one-way ANOVA's and Bonferoni post hoc tests. Pound signs indicate significant differences $(P<0.05)$ from corresponding control leaves based on Kruskall-Wallis one-way ANOVAs on ranks and Dunn's post hoc tests

increase for herbivore-treated plants $(t=3.938, P=0.002$; Fig. 8b).

The accumulation of mono- and sesquiterpenes in leaf 4 after treatment followed a comparable pattern: a gradual increase from control to mechanical damage and herbivory (ANOVA: monoterpenes, $F=8.13, P=0.004$; sesquiterpenes, $F=27.43, \quad P<0.001$; Fig. 8c,d). Levels of monoterpenes were elevated after herbivory in comparison to the controls $(t=4.029, P=0.001)$. Levels of sesquiterpenes were elevated after mechanical damage $(t=5.115, P<0.001)$ and herbivory $(t=7.197, P<0.001)$ in comparison to the controls.

\section{Discussion}

Cotton (G. hirsutum) accumulates a large variety of terpenes constitutively, including monoterpenes $\left(\mathrm{C}_{10}\right)$, sesquiterpenes $\left(\mathrm{C}_{15}\right)$, and terpenoid aldehydes $\left(\mathrm{C}_{15}, \mathrm{C}_{25}\right.$, and $\mathrm{C}_{30}$ ). This study is the first to describe the accumulation of all three of these classes after actual or simulated a
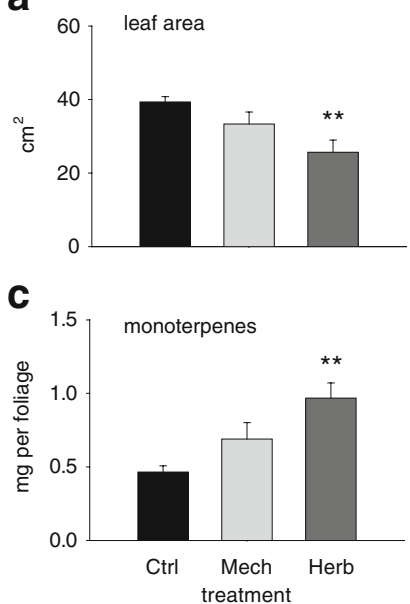

b

d

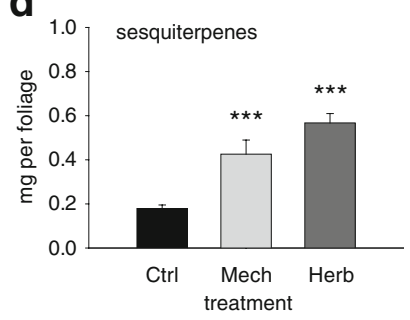

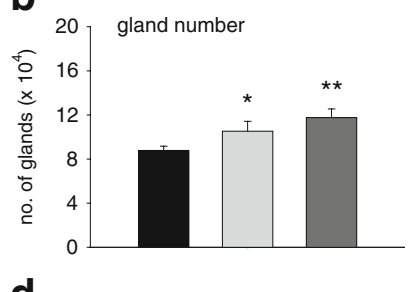

Fig. 8 Mean $( \pm$ SE, $N=6)$ leaf area, number of glands, and monoterpene- and sesquiterpene levels of leaf 4 from 3-week-old Gossypium hirsutum plants, which were either damaged mechanically at leaves 1 and 2 (Mech), fed upon by larvae of Spodoptera littoralis (Herb) on one cotyledon, leaves 1 and 2, or left as untreated controls $(C t r l)$. Asterisks indicate significant differences from corresponding control leaves based on one-way ANOVAs (a), on analyses of codeviance with leaf area as covariable (b), and ANCOVAs with leaf area as covariable $(\mathbf{c}, \mathbf{d}) .{ }^{*} P<0.05 ; * * P<0.01 ; * * * P<0.001$ herbivory. Increased levels of terpenoids were observed in the total foliage 1 week after mechanical damage, feeding by Spodoptera littoralis caterpillars, or treatment with JA, in comparison to the untreated controls. A closer look revealed that, after damage to older leaves (leaves 2 and 3 numbered from the base), the increase was restricted mainly to young leaves (leaves 5-7). Similarly, studies on cotton that investigate the effects of herbivory by larvae of $S$. exigua and the wireworm Agriotes lineatus also showed elevated concentrations of terpenoid aldehydes in young cotton leaves (McAuslane et al. 1997; McAuslane and Alborn 1998; Bezemer et al. 2004). Such an induction pattern is in agreement with ODT, which predicts that an increase in the accumulation of defense chemicals occurs preferentially in plant parts with the highest fitness value such as young tissues or reproductive organs (McKey 1979; Frischknecht et al. 1987; Ohnmeiss and Baldwin 2000).

All three classes of cotton terpenoids are stored in subepidermal pigment glands found in leaves and other organs. After treatment, G. hirsutum displayed two ways to achieve elevated terpenoid accumulation: (1) production of additional glands and (2) increased filling of existing glands (Fig. 6). We showed that production of additional glands was restricted to leaves that were still under development or newly formed after treatment. This trend also has been observed after attack by spider mites or larvae of $S$. exigua on cotton (McAuslane et al. 1997; Agrawal and Karban 2000). In other plants, such as birch and tomato, an elevated number of defense structures like glandular trichomes is also produced in young leaves after induction by herbivores (Boughton et al. 2005; Valkama et al. 2005). Besides the fact that, according to ODT, plants have been selected to increase their resistance to herbivores especially in young tissue, the formation of subepidermal pigment glands in cotton might be necessarily restricted to newly developing leaves because of developmental constraints.

In counting the number of cotton leaf glands under a stereomicroscope, we may have overestimated the production of new glands after treatment if herbivory triggered the filling of pre-existing glands that were unpigmented $(\mathrm{H}$. T. Alborn, personal communication). However, by using several microscopic techniques, we did not find any evidence for unfilled glands in the leaves analyzed. Therefore, we assume that actual or simulated herbivory does indeed induce increased numbers of glands in cotton.

The increased filling of existing glands with terpenoids was shown in the youngest leaves of induced plants for all major terpenoid classes. However, considerable differences in the magnitude of this additional accumulation were observed among individual terpenoid compounds. Among terpenoid aldehydes, levels of heliocides $\mathrm{H}_{1}$ and $\mathrm{H}_{4}$, showed the highest increase after treatments. Other studies on cotton species also have demonstrated that these two 
heliocides increase more than $\mathrm{H}_{2}, \mathrm{H}_{3}$, and hemigossypolone (HGQ) after herbivory by Spodoptera species (McAuslane et al. 1997; McAuslane and Alborn 1998; Agrell et al. 2004; Bezemer et al. 2004). Here, we showed that levels of $(E)-\beta$-ocimene increased in a magnitude similar to $\mathrm{H}_{1}$ and $\mathrm{H}_{4}$, and that this compound increased most among monoterpenes and sesquiterpenes. Interestingly, $(E)-\beta$-ocimene is a direct precursor in the formation of $\mathrm{H}_{1}$ and $\mathrm{H}_{4}$, combining with hemigossypolone in a Diels-Alder-type reaction (Stipanovic et al. 1978a; Fig. 2). Therefore, in non-treated plants, the biosynthesis of this monoterpene could represent a limiting step in the production of the appropriate heliocides. This proposition is supported by the fact that, in cotyledons of G. hirsutum, which do not contain any heliocides, hemigossypolone is present (S. Opitz, unpublished), but (E)- $\beta$-ocimene is absent. A comparable regulation mechanism that involves myrcene could determine the levels of $\mathrm{H}_{2}$ and $\mathrm{H}_{3}$ (Stipanovic et al. 1977, 1978b).

Our study compared the terpenoid content of total cotton foliage after three different treatments and showed a gradual increase in terpenoid levels in the following order: mechanical damage with a fabric pattern wheel, herbivory by $S$. littoralis caterpillars, and application of JA. However, a single incidence of mechanical injury is hard to compare with continuous feeding damage by an insect. Studies on lima bean have demonstrated that both the intensity and frequency of mechanical damage can alter the reaction of a plant (Mithöfer et al. 2005). This is consistent with the results of experiment 2 where more frequent mechanical damage caused significantly higher numbers of glands (Fig. 8), a response not detectable after the less frequent mechanical damage in experiment 1 (Fig. 5 and 6). However, in both experiments, herbivory induced stronger reactions of plants than mechanical damage. Elicitors found in the regurgitate of herbivores are known to trigger the biosynthesis of defense metabolites (Alborn et al. 1997). If such elicitors play a role in cotton defense reactions, mechanical injury may never result in terpenoid accumulation comparable to that caused by herbivory.

The strongest increase in both terpenoid and gland production appeared in plants that were treated with JA, a ubiquitous plant hormone known to mediate defense responses to biotic and abiotic stresses (Browse 2005). A previous study with cotton showed that the application of the methylated derivative, methyl jasmonate, induced the synthesis and emission of volatile terpenes, a response also observed for herbivore-damaged plants (RodriguezSaona et al. 2001). Obviously, JA plays an important role in mediating damage-induced signaling in G. hirsutum. Given the effects of exogenous application, herbivory can be assumed to trigger elevated internal levels of JA as in other species (Baldwin et al. 1997; Creelman and Mullet 1997). For example, in tobacco, lima bean, or maize, internal JA levels were determined in ranges of single nanograms per gram fresh weight, showing 20 - to 40 -fold increases within the first hours after induction (Baldwin et al. 1997; Koch et al. 1999; Schmelz et al. 2003). However, internal JA levels of cotton still need to be investigated. If the irrigation of plants with $100 \mu \mathrm{M} \mathrm{JA}$ in our study led to a non-physiological high internal concentration of JA, this could explain why JA treatment induced terpenoid accumulation to a greater extent than herbivory. We observed additionally that JA inhibited leaf development, a response also seen in other plants (Sembdner and Parthier 1993).

Studies on the induction of chemical defense in plants after herbivory always raise questions about the specificity of such reactions to particular enemies. Certain plants have been shown to induce different spectra of defenses in response to different herbivores (Turlings et al. 1998; Traw and Dawson 2002; Delphia et al. 2007). However, in this study, we did not find substantial differences in the pattern of induction among treatments for the major terpenoids measured (see Table 1). The amounts of single compounds varied in magnitude, leading to changes in the terpenoid profile, but these profile changes tended to be comparable among treatments. The induction of elevated terpenoid accumulation in leaves of G. hirsutum may thus be a nonspecific reaction of plants to damage. Similar non-specific reactions to damage are known for terpenes in other species (Banchio et al. 2005), as well as for alkaloids (Frischknecht et al. 1987; Baldwin et al. 1997), phenolics (Cipollini 1997), and glucosinolates (Bodnaryk 1992).

The fact that cotton plants react to damage with elevated levels of terpenoids accumulated in the subepidermal pigment glands of their foliage suggests that these compounds function in plant defense. Caterpillar species such as S. exigua or Heliothis virescens prefer feeding on glandless instead of glanded cultivars of G. hirsutum, thus supporting the argument that the gland terpenes play a key role in defense of cotton against herbivores (Montandon et al. 1986; McAuslane and Alborn 2000). Leaf material from plants of glanded cultivar lines that had been induced by herbivory showed increased deterrent or toxic effects on Spodoptera species compared to material from uninduced plants, a finding thought to be due to their elevated contents of terpenoid aldehydes (Alborn et al. 1996; McAuslane et al. 1997; Anderson et al. 2001). Indeed, terpenoid aldehydes such as gossypol, hemigossypolone, and the heliocides $\mathrm{H}_{1}$ and $\mathrm{H}_{2}$ exhibit strong toxicity to caterpillars of $H$. virescens and Pectinophora gossypiella after addition to artificial diet (Elliger et al., 1978). While the feeding deterrent effects of induced cotton foliage are usually attributed to elevated terpenoid aldehydes contents (Hedin et al. 1992; McAuslane et al. 1997; McAuslane and Alborn 2000), we showed that cotton plants also increase their 
levels of monoterpenes and sesquiterpenes. Thus, these compounds may also participate in defense against herbivores. A sesquiterpene, caryophyllene oxide has been demonstrated to synergize the negative effect of gossypol, the dominant terpenoid aldehyde in roots and seeds of cotton, on larval development of $H$. virescens (Gunasena et al. 1988). Additionally, caryophyllene retarded the growth and delayed the time of development of these larvae. Other studies have shown that single sesquiterpenes such as $\beta$ bisabolene impair the development of insect herbivores and deter them from feeding (Bowers et al. 1976; GonzalezColoma et al. 1995; Zipfel 2007).

Beside their function against herbivores, terpenoids are also considered to play a defensive role against fungi or pathogens. Because plants are exposed especially to infestation at wound sites, the elevated terpenoid levels in damaged leaves might have a critical role in helping plants to cope with pathogens. For cotton, studies have shown that certain terpenoid aldehydes possess antifungal and antipathogen activities (Zhang et al. 1993; Abraham et al. 1999). A good example for the antibiotic activity of terpenoids in other species comes from conifers where the growth and germination of bark beetle associated pathogens is inhibited (Keeling and Bohlmann 2006). In addition, analyses of terpene-rich essential oils from a variety of plant species have shown antibacterial and antifungal activities, indicating the potential role of these substances in plant defense (Oyedeji and Afolayan 2005; Ozer et al. 2007).

In summary, our results demonstrate that elevated levels of terpenoids in cotton leaves after real and simulated herbivory represent a general wound response that is mediated by JA. The increase in terpenoids is due to the production of additional glands, in which terpenoids are stored, as well as the increased filling of existing glands. As all three classes of terpenoids (monoterpenes, sesquiterpenes, and terpenoid aldehydes) were elevated after damage, these substances may act synergistically in defense against herbivores or pathogens (Stipanovic et al. 1988).

Acknowledgment We thank Bettina Raguschke and Carsten Köhler for help with the preparation of all leaf samples; Steffen Harzsch for microscopic work; Sybille Unsicker, Susanne Textor, Michael Reichelt and Jan-Willem Dekraker for discussing the manuscript; the gardeners of our institute for growing the plants; and Syngenta Crop Protection AG for providing us with Spodoptera littoralis eggs. Financial support was provided by the Deutsche Forschungsgemeinschaft (DFG: Az. OP 93/1-1) and the Max Planck Society.

Open Access This article is distributed under the terms of the Creative Commons Attribution Noncommercial License which permits any noncommercial use, distribution, and reproduction in any medium, provided the original author(s) and source are credited.

\section{References}

Abraham, K. J., Pierce, M. L., and Essenberg, M. 1999. The phytoalexins desoxyhemigossypol and hemigossypol are elicited by Xanthomonas in Gossypium cotyledons. Phytochemistry $52: 829-836$

AgrawAL, A. A., and Karban, R. 1999. Why induced defenses may be favored over constitutive strategies in plants, pp. 45-61, in R. Tollrian, and C. D. Harvell (eds.). The Ecology and Evolution of Inducible DefensesPrinceton University Press, Princeton.

Agrawal, A. A., and Karban, R. 2000. Specificity of constitutive and induced resistance: pigment glands influence mites and caterpillars on cotton plants. Entomol. Exp. Appl. 96:39-49.

Agrell, J., Anderson, P., Oleszek, W., Stochmal, A., and Agrell, C. 2004. Combined effects of elevated CO2 and herbivore damage on alfalfa and cotton. J. Chem. Ecol. 30: 2309-2324.

Alborn, H. T., RöSE, U. S. R., and MCAuslane, H. J. 1996. Systemic induction of feeding deterrents in cotton plants by feeding of Spodoptera spp. larvae. J. Chem. Ecol. 22:919-932.

Alborn, T., Turlings, T. C. J., Jones, T. H., Stenhagen, G., Loughrin, J. H., and Tumlinson, J. H. 1997. An elicitor of plant volatiles from beet armyworm oral secretion. Science 276:945-949.

Anderson, P., Jonsson, M., and Morte, U. 2001. Variation in damage to cotton affecting larval feeding preference of Spodoptera littoralis. Entomol. Exp. Appl. 101:191-198.

BALDWIN, I. T. 1988. The alkaloidal responses of wild tobacco to real and simulated herbivory. Oecologia 77:378-381.

BALDWIN, I. T. 2001. An ecologically motivated analysis of plantherbivore interactions in native tobacco. Plant Physiol. 127:1449-1458.

BALdwin, I. T., Zhang, Z. P., DiaB, N., OHNMEISS, T. E., Mccloud, E. S., LYNDS, G. Y., and Schmelz, E. A. 1997. Quantification, correlations and manipulations of wound-induced changes in jasmonic acid and nicotine in Nicotiana sylvestris. Planta 201: 397-404.

BANChio, E., Zygadlo, J., and Valladares, G. R. 2005. Quantitative variations in the essential oil of Minthostachys mollis (Kunth.) Griseb. in response to insects with different feeding habits. J. Agric. Food Chem. 53:6903-6906.

Berenbaum, M. R., and ZangerL, A. R. 1999. Coping with life as a menu option: inducible defenses of the wild parsnip, pp. 10-32, in R. Tollrian, and C. D. Harvell (eds.). The Ecology and Evolution of Inducible DefensesPrinceton University Press, Princeton.

BEZEMER, T. M., WAGENAAR, R., VAN DAM, N. M., VAN DER PUTTEN, W. H., and WACKERS, F. L. 2004. Above- and below-ground terpenoid aldehyde induction in cotton, Gossypium herbaceum, following root and leaf injury. J. Chem. Ecol. 30:53-67.

BODNARYK, R. P. 1992. Effects of wounding on glucosinolates in the cotyledons of oilseed rape and mustard. Phytochemistry 31:2671-2677.

Boughton, A. J., Hoover, K., and Felton, G. W. 2005. Methyl jasmonate application induces increased densities of glandular trichomes on tomato, Lycopersicon esculentum. J. Chem. Ecol. 31:2211-2216.

Bowers, W. S., Ohta, T., Cleere, J. S., and Marsella, P. A. 1976. Discovery of insect anti-juvenile hormones in plants. Science 193:542-547.

Brown, P. D., Tokuhisa, J. G., eichelt, M., and Gershenzon, J. 2003. Variation of glucosinolate accumulation among different organs and developmental stages of Arabidopsis thaliana. Phytochemistry 62:471-481.

BRowSE, J. 2005. Jasmonate: an oxylipin signal with many roles in plants. Plant Hormones 72:431-456. 
Buckingham, J. (eds.). 1994. Dictionary of Natural Products. Chapman \& Hall, London.

CipollinI, D. F. 1997. Wind-induced mechanical stimulation increases pest resistance in common bean. Oecologia 111:84-90.

Crawley, M. J. 2002. Statistical Computing. Wiley, West Sussex.

Creelman, R. A., and Mullet, J. E. 1997. Biosynthesis and action of jasmonates in plants. Annu. Rev. Plant Physiol. Plant Mol. Biol. 48:355-381.

Croxford, A. C., Edwards, P. J., and Wratten, S. D. 1989. Temporal and spatial variation in palatability of soybean and cotton leaves following wounding. Oecologia 79:520-525.

DAVIS, G. D., and EsSENBERG, M. 1995. (+)-Delta-cadinene is a product of sesquiterpene cyclase activity in cotton. Phytochemistry 39:553-567.

DelphiA, C. M., Mescher, M. C., and De moraes, C. M. 2007. Induction of plant volatiles by herbivores with different feeding habits and the effects of induced defenses on host-plant selection by thrips. J. Chem. Ecol. 33:997-1012.

Elliger, C. A., Chan, B. G., and Waiss, A. C. 1978. Relative toxicity of minor cotton terpenoids compared to gossypol. $J$. Econ. Entomol. 71:161-164.

Elzen, G. W., Williams, H. J., Bell, A. A., Stipanovic, R. D., and VINSON, S. B. 1985. Quantification of volatile terpenes of glanded and glandless Gossypium hirsutum cultivars and lines by gas chromatography. J. Agric. Food Chem. 33:1079-1082.

FAHN, A. 1979. Secretory Tissues in Plants. Academic, London.

FrischKNeChT, P. M., BATTIG, M., and BAUMANN, T. W. 1987. Effect of drought and wounding stress on indole alkaloid formation in Catharanthus roseus. Phytochemistry 26:707-710.

GERSHENZON, J. 1994. Metabolic costs of terpenoid accumulation in higher plants. J. Chem. Ecol. 20:1281-1328.

Gershenzon, J., and Croteau, R. 1991. Terpenoids, pp. 165-219, in G. A. Rosenthal, and M. R. Berenbaum (eds.). Herbivores, Vol. 1: Their Interaction with Secondary Plant MetabolitesAcademic, San Diego.

Gershenzon, J., and Dudareva, N. 2007. The function of terpene natural products in the natural world. Nat. Chem. Biol. 3:408-414.

Gershenzon, J., Mcconkey, M. E., and Croteau, R. B. 2000. Regulation of monoterpene accumulation in leaves of peppermint. Plant Physiol. 122:205-213.

Gonzalez-coloma, A., Reina, M., Cabrera, R., Castanera, P., and Gutierrez, C. 1995. Antifeedant and toxic effects of sesquiterpenes from Senecio palmensis to Colorado potato beetle. J. Chem. Ecol. 21:1255-1270.

Gunasena, G. H., Vinson, S. B., Williams, H. J., and Stipanovic, R. D. 1988. Effects of caryophyllene, caryophyllene oxide, and their interaction with gossypol on the growth and development of Heliothis virescens (F) (Lepidoptera, Noctuidae). J. Econ. Entomol. 81:93-97.

HARBORNE, J. B. 1991. Flavonoid pigments, pp. 389-426, in G. A. Rosenthal, and M. R. Berenbaum (eds.). Herbivores, Vol. 1: Their Interaction with Secondary Plant Metabolites Academic, San Diego.

HARTMANN, T., and ZIMMER, M. 1986. Organ-specific distribution and accumulation of pyrrolizidine alkaloids during the life history of two annual Senecio species. J. Plant Physiol. 122:67-80.

Hedin, P. A., PARROTt, W. L., and Jenkins, J. N. 1992. Relationships of glands, cotton square terpenoid aldehydes, and other allelochemicals to larval growth of Heliothis virescens (Lepidoptera, Noctuidae). J. Econ. Entomol. 85:359-364.

KARBAN, R., and CAREY, J. R. 1984. Induced resistance of cotton seedlings to mites. Science 225:53-54.

KeEling, C. I., and Bohlmann, J. 2006. Genes, enzymes and chemicals of terpenoid diversity in the constitutive and induced defence of conifers against insects and pathogens. New Phytol. 170:657-675.
Koch, T., Krumm, T., Jung, V., Engelberth, J., and Boland, W. 1999. Differential induction of plant volatile biosynthesis in the lima bean by early and late intermediates of the octadecanoidsignaling pathway. Plant Physiol. 121:153-162.

MCauslane, H. J., and Alborn, H. T. 1998. Systemic induction of allelochemicals in glanded and glandless isogenic cotton by Spodoptera exigua feeding. J. Chem. Ecol. 24:399-416.

MCAUSlane, H. J., and AlBORN, H. T. 2000. Influence of previous herbivory on behavior and development of Spodoptera exigua larvae on glanded and glandless cotton. Entomol. Exp. Appl. 97:283-291.

Mcauslane, H. J., Alborn, H. T., and Toth, J. P. 1997. Systemic induction of terpenoid aldehydes in cotton pigment glands by feeding of larval Spodoptera exigua. J. Chem. Ecol. 23:2861-2879.

Mcconkey, M. E., Gershenzon, J., and Croteau, R. B. 2000. Developmental regulation of monoterpene biosynthesis in the glandular trichomes of peppermint. Plant Physiol. 122:215-223.

MCKEY, D. 1979. Distribution of secondary compounds in plants, pp. 45-133, in G. A. Rosenthal, and D. H. Janzen (eds.). Herbivores: Their Interaction with Secondary MetabolitesAcademic, New York

MithÖFER, A., WANNER, G., and BOLAND, W. 2005. Effects of feeding Spodoptera littoralis on lima bean leaves. II. Continuous mechanical wounding resembling insect feeding is sufficient to elicit herbivory-related volatile emission. Plant Physiol. 137: 1160-1168.

Montandon, R., Williams, H. J., Sterling, W. L., Stipanovic, R. D., and Vinson, S. B. 1986. Comparison of the development of Alabama argillacea (Hubner) and Heliothis virescens (F) (Lepidoptera, Noctuidae) fed glanded and glandless cotton leaves. Environ. Entomol. 15:128-131.

OhNmEISs, T. E., and BALDwIN, I. T. 2000. Optimal Defense Theory predicts the ontogeny of an induced nicotine defense. Ecology $81: 1765-1783$.

OPITZ, S., and SCHNEIDER, B. 2002. Organ-specific analysis of phenylphenalenone-related compounds in Xiphidium caeruleum. Phytochemistry 61:819-825.

OyedeJI, O. A., and Afolayan, A. 2005. Comparative study of the essential oil composition and antimicrobial activity of Leonotis leonurus and L. ocymifolia in the Eastern Cape, South Africa. S. Afr. J. Bot. 71:114-116.

Ozer, H., Sokmen, M., Gulluce, M., Adiguzel, A., Sahin, F., SoKmen, A., KILIC, H., and Baris, O. 2007. Chemical composition and antimicrobial and antioxidant activities of the essential oil and methanol extract of Hippomarathrum microcarpum (Bieb.) from Turkey. J. Agric. Food Chem. 55:937-942.

Porter, A. J. R., Morton, A. M., Kiddle, G., Doughty, K. J., and WALLSGROVE, R. M. 1991. Variation in the glucosinolate content of oilseed rape Brassica napus L. leaves I. Effect of leaf age and position. Ann. Appl. Biol. 118:461-468.

RHOADES, D. F. 1979. Evolution of plant chemical defense against herbivores, pp. 3-54, in G. A. Rosenthal, and D. H. Janzen (eds.). Herbivores: Their Interaction with Secondary Metabolites. Academic, New York.

Rodriguez-SaOna, C., Crafts-Brander, S. J., Pare, P. W., and HENNEBERRY, T. J. 2001. Exogenous methyl jasmonate induces volatile emissions in cotton plants. J. Chem. Ecol. 27:679-695.

SCANLON, T. S., and WiLliS, E. D. 1985. Calculation of flame ionization detector relative response factors using the effective carbon number concept. J. Chromatogr. Sci. 23:333-340.

Schmelz, E. A., Alborn, H. T., BAnchio, E., and Tumlinson, J. H. 2003. Quantitative relationships between induced jasmonic acid levels and volatile emission in Zea mays during Spodoptera exigua herbivory. Planta 216:665-673.

Sembdner, G., and PARTHIER, B. 1993. The biochemistry and the physiological and molecular actions of jasmonates. Annu. Rev. Plant Physiol. Plant Mol. Biol. 44:569-589. 
Stipanovic, R. D., Bell, A. A., O'Brien, D. H., Lukefahr, M. J., and Drawer, P. O. 1977. Heliocide H2: an insecticidal sesterterpenoid from cotton Gossypium. Tetrahedron Lett. 6:567-570.

Stipanovic, R. D., Bell, A. A., O'BRIEN, D. H., and Lukefahr, M. J. 1978a. Heliocide H1: a new insecticidal 25-carbon terpenoid from cotton Gossypium hirsutum. J. Agric. Food Chem. 26:115118.

Stipanovic, R. D., Bell, A. A., O'Brien, D. H., and Lukefahr, M. J. 1978b. Heliocide H3: An insecticidal terpenoid from Gossypium hirsutum. Phytochemistry 17:151-152.

Stipanovic, R. D., Altman, D. W., Begin, D. L., Greenblatt, G. A., and BenEDICT, J. H. 1988. Terpenoid aldehydes in upland cottons analysis by aniline and HPLC methods. J. Agric. Food Chem. 36:509-515.

TraW, M. B., and DAWSON, T. E. 2002. Differential induction of trichomes by three herbivores of black mustard. Oecologia 131:526-532.

Turlings, T. C. J., Bernasconi, M., Bertossa, R., Bigler, F., CALOZ, G., and DORN, S. 1998. The induction of volatile emissions in maize by three herbivore species with different feeding habits: Possible consequences for their natural enemies. Biol. Control 11:122-129.
Valkama, E., Koricheva, J., Ossipov, V., Ossipova, S., Haukioja, E., and PiHLaja, K. 2005. Delayed induced responses of birch glandular trichomes and leaf surface lipophilic compounds to mechanical defoliation and simulated winter browsing. Oecologia 146:385-393.

VAN POECKE, R. M. P., and DiCKe, M. 2002. Induced parasitoid attraction by Arabidopsis thaliana: involvement of the octadecanoid and the salicylic acid pathway. J. Exp. Bot. 53:1793-1799.

VAZQUeZ-Flota, F., CARRILlO-PECH, M., Minero-GarCia, Y., and MIRANDA-HAM, M. D. 2004. Alkaloid metabolism in wounded Catharanthus roseus seedlings. Plant Physiol. Biochem. 42:623628.

WitTstock, U., and Gershenzon, J. 2002. Constitutive plant toxins and their role in defense against herbivores and pathogens. Curr. Opin. Plant Biol. 5:300-307.

Zhang, J., Mace, M. E., Stipanovic, R. D., and Bell, A. A. 1993. Production and fungitoxicity of the terpenoid phytoalexins in cotton: inoculated with Fusarium oxysporum f. sp. vasinfectum. J. Phytopathol. 139:247-252.

ZIPFEL, C. 2007. The Effect of Bt-Transformation and Various Environmental Factors on the Volatile Emission of Maize: Potential Influence on Direct and Indirect Defense Against Herbivores. PhD dissertation, Friedrich-Schiller-University, Jena. 